\title{
Prostate Acinar Adenocarcinoma, Oncocytic Variant
}

National Cancer Institute

\section{Source}

National Cancer Institute. Prostate Acinar Adenocarcinoma, Oncocytic Variant. NCI

Thesaurus. Code C39884.

A variant of acinar prostate adenocarcinoma characterized by the presence of malignant large cells with granular eosinophilic cytoplasm. 